\title{
Morphological Changes in Carotid Arteries in Stroke Cases
}

\author{
Guna Bahadur Thapa, ${ }^{1}$ Alin Sundas, ${ }^{2}$ Raj Kumar Rauniyar ${ }^{2}$ \\ 'Department of Radiology, Shree Birendra Hospital, Chhauni, Kathmandu, Nepal, ${ }^{2}$ Department of Radiology, \\ BP Koirala Institute of Health Sciences, Dharan, Nepal.
}

\begin{abstract}
Introduction: Majority of stroke is due to ischemic infarction and occurs in carotid artery territory. The extra cranial parts of carotid arteries are the common sites for the atherosclerotic plaque formation. Ultrasonography is the first line of investigation for screening of the carotid artery diseases to localize and characterize the plaques. Objective was to study the morphological changes in extra cranial part of carotid arteries in cases of ischemic infarction using Ultrasonography.
\end{abstract}

Methods: It was an institution based prospective study and convenience sampling method was used. Computed Tomography proven ischemic infarct, lacunar infarction and transient ischemic infarction cases were included in the study.

Results: Fifty four cases were included in the study. Mean of Intimo-medial Complex Thickness was $0.89 \mathrm{~mm}$ and $0.88 \mathrm{~mm}$ in right and left side respectively. Sixty five percent cases had plaque in extra cranial part of carotid artery. Ninety three percent of plaque was found in and adjacent to the carotid bulb region. Ipsilateral plaque was found in $76 \%$ and $65 \%$ cases on right and left side respectively. Fifty three percent of cases had soft plaque. Majority of cases had less than $50 \%$ narrowing of the lumen diameter in term of cross-sectional area due to plaque. Thirteen $(24 \%)$ cases had plaque in internal carotid artery.

Conclusions: Carotid ultrasound can be used for screening of the asymptomatic but high-risk cases and following up of the symptomatic cases to plan for necessary management as required.

Keywords: carotid artery, carotid ultrasonography, ischemic infarction, plaque.

\section{INTRODUCTION}

Stroke is the second leading cause of death in the world after ischemic heart disease. ${ }^{1}$ Majority of stroke is due to ischemic infarction. About $90 \%$ of the ischemic stroke occurs in carotid artery territory. ${ }^{2}$ The extra cranial part of internal carotid artery (ICA), carotid bulb and distal part of common carotid artery (CCA) are the common sites for the atherosclerotic plaque formation causing main source of thrombo-embolism and the severe flow limiting stenosis. Plaque is mainly located in ICA within $2 \mathrm{~cm}$ of the carotid bifurcation and this region is easy to access and examine too. ${ }^{3}$
Ultrasonography is the first line of investigation for screening of the carotid artery diseases. ${ }^{3}$ It will localize the plaque, its characteristics, percentage and extent of stenosis. It is easy to perform, can be done repeatedly, does not have any proven risk factor and is cost effective also. 4

Correspondence: Dr. Guna B Thapa, Department of Radiology, Kosair Children's Hospital, Louisville, Kentucky 40202 USA. Email: drgb.thapa@gmail.com, Phone: 502-303-4664. 
This study was designed to find out the status of extracranial part of carotid arteries in patients with ischemic infarction who visited B P Koirala Institute of Health Sciences (BPKIHS), Dharan, Nepal.

\section{METHODS}

It was a prospective, observational study with convenience sampling method was used. Fifty four Computed Tomography (CT) proven, clinically stable, ischemic infarction, lacunar infarction and transient ischemic infarction (TIA) cases were included in the study. This study was carried out at Radiology department of BPKIHS, Dharan, Nepal from May 2004 to May 2005. Informed consent was taken from the patients or legal next of kin. Guidelines of the scientific committee of BPKIHS, Dharan were strictly followed. Infarction due to other known pathology like cardiac or hematological reasons and hemorrhagic stroke cases were excluded from the study. Information on demographic characteristics and risk factors was collected using a structured questionnaire.

Objective was to study the morphological changes in extra cranial part of carotid arteries in cases of ischemic infarction using Ultrasonography.

All included patients underwent high-resolution carotid ultrasound examination with $7.5 \mathrm{MHz}$ linear probe to evaluate the morphological characteristics of the vessels. Lumen diameter, Intimo-medial Complex Thickness (IMT), characterization of plaques was recorded and calculation of luminal diameter reduction in term of cross-sectional area (CSA) was done by using the existing program in the US machine itself.

Distribution of the plaques were recorded and classified according to Gray-Weale criteria: (1) Type I: dominantly echolucent with a thin echogenic cap, (2) Type II: predominantly echolucent, (3) Type III: substantially echogenic and (4) Type IV: echogenic/calcified plaque. ${ }^{5}$

The Quantification of the degree of narrowing was categorized as (i) normal (ii) $<50 \%$ narrowing (iii) $50 \%-69 \%$ narrowing (iv) $70 \%-99 \%$ narrowing to near occlusion and (v) total occlusion as per Society of Radiologists in Ultrasound Consensus Conference criteria. ${ }^{6}$

Data analysis was done with SPSS 10.0 software package. Difference between mean were tested for statistical significance by the Pearson chi-Square test. were included in the study and Mean age is 61.9 years (mean age of male and female was 62.2 and 61 years respectively). Seventy four percent had large infarction, $13 \%$ had lacunar infraction and 7\% TIA. Lumen diameter of the CCA was ranging from $4.8 \mathrm{~mm}$ to $11.1 \mathrm{~mm}$; the mean value was $8.2 \mathrm{~mm}$ and $8.4 \mathrm{~mm}$ in right and left side respectively. Mean value of IMT was $0.89 \mathrm{~mm}$ and $0.88 \mathrm{~mm}$ for right and left CCA respectively but the actual range was from $0.5 \mathrm{~mm}$ to $1.5 \mathrm{~mm}$. Thirty five out of $54(65 \%)$ cases had plaque; however 17 cases had the plaque either in both CCA and ICA and/or both sides. Therefore the actual number of plaque was 57 (found in 35 cases). Forty three percent had neurological deficit on right side and $31 \%$ on left side. Ipsilateral plaque was found in $76 \%$ and $65 \%$ cases on right and left side respectively. Ninety three percent of the plaque was found in and near to carotid bifurcation region $(23 \%$ in proximal ICA, $33 \%$ in carotid bulb and $37 \%$ in distal CCA). Type I, II, III and IV plaques were $18 \%, 35 \%, 43 \%$ and $4 \%$ respectively. CSA data showed the majority of the cases had less than $50 \%$ narrowing. Twenty one percent cases had $50-69 \%$ narrowing and another $21 \%$ cases had $70-$ $99 \%$ luminal narrowing. Thirteen (24\%) cases had plaque in extracranial part of ICA (Table 1, 2).

\begin{tabular}{|lll|}
\hline \multicolumn{2}{|c|}{ Table 1. The general characteristics of the data. } \\
\hline \multirow{5}{*}{ Age (Years) } & $40-49$ & $n(\%)$ \\
& $50-59$ & $15(11 \%)$ \\
& $60-69$ & $18(33 \%)$ \\
& $70-79$ & $12(22 \%)$ \\
Sex & 80 and above & $3(6 \%)$ \\
& Male & $38(70 \%)$ \\
Types of Plaque & Female & $16(30 \%)$ \\
& Type I & $10(18 \%)$ \\
& Type III & $20(35 \%)$ \\
Type IV & $25(43 \%)$ \\
Plaque & Proximal ICA & $2(4 \%)$ \\
& Carotid bulb & $13(23 \%)$ \\
plaque & Distal CCA & $21(37 \%)$ \\
& Mid/Prox. CCA & $4(7 \%)$ \\
& Rt. CCA & $21(72 \%)$ \\
& Rt. ICA & $8(28 \%)$ \\
& Lt. CCA & $23(82 \%)$ \\
& Lt. ICA & $5(18 \%)$ \\
& & $54(100 \%)$ \\
\hline
\end{tabular}

\section{RESULTS}

Fifty four cases with age ranging from 40-92 years 
Table 2. The overview of the plaque distribution and characterization.

\begin{tabular}{|c|c|c|c|c|c|c|c|}
\hline \multirow{2}{*}{ Side of stroke } & \multirow{2}{*}{ Number of Plaque } & \multirow{2}{*}{$\begin{array}{l}\text { Number of } \\
\text { patients }\end{array}$} & \multicolumn{2}{|c|}{ Plaque location } & \multirow{3}{*}{$\begin{array}{l}\text { Lt. } \\
\text { CCA }\end{array}$} & \multirow[b]{2}{*}{$\begin{array}{l}\text { Lt. } \\
\text { ICA }\end{array}$} & \multirow[b]{2}{*}{ Total } \\
\hline & & & Rt. CCA & Rt. ICA & & & \\
\hline \multirow[b]{2}{*}{$\begin{array}{l}\text { Right side infarct } \\
n=21\end{array}$} & Ipsilateral & 9 & 6 & 5 & & & 11 \\
\hline & $\begin{array}{l}\text { Contralateral } \\
\text { Bilateral } \\
\text { No plaque }\end{array}$ & $\begin{array}{l}1 \\
4 \\
7\end{array}$ & 4 & 1 & 3 & 1 & $\begin{array}{l}1 \\
9\end{array}$ \\
\hline \multirow{2}{*}{$\begin{array}{l}\text { Left side infarct } \\
\mathrm{n}=22\end{array}$} & Ipsilateral & 6 & & & 6 & 1 & 7 \\
\hline & $\begin{array}{l}\text { Bilateral } \\
\text { No plaque }\end{array}$ & $\begin{array}{l}7 \\
9\end{array}$ & 7 & 2 & 6 & 2 & 19 \\
\hline \multirow{3}{*}{$\begin{array}{l}\text { Both side infarct } \\
n=7\end{array}$} & Unilateral & 2 & 1 & & 1 & & 2 \\
\hline & Bilateral & 1 & 1 & & 1 & & 2 \\
\hline & No plaque & 4 & & & & & \\
\hline \multirow{3}{*}{ No infarct $n=4$} & Ipsilateral & 1 & & & 1 & & 1 \\
\hline & $\begin{array}{l}\text { Bilateral } \\
\text { No plaque }\end{array}$ & $\begin{array}{l}2 \\
1\end{array}$ & 2 & & 2 & 1 & 5 \\
\hline & Total & 54 & 21 & 8 & 23 & 5 & 57 \\
\hline
\end{tabular}

\section{DISCUSSION}

In literature review, $90 \%$ of the ischemic stroke occurs in carotid territory and it is mainly located in ICA within $2 \mathrm{~cm}$ of the carotid bifurcation. ${ }^{2,3}$ In the present study, $93 \%$ cases had infarction in carotid artery territory and $93 \%$ plaque was found in and adjacent to the carotid bulb (including ICA, Carotid bulb and distal part of CCA). Majority of stroke cases $(76 \%$ and $65 \%$ case on right and left side respectively) had ipsilateral plaque.

Seventy four percent had large infarction, $13 \%$ had lacunar infraction and $7 \%$ TIA. These findings are similar to data mentioned by Smith WS et al in Harrison's Principle of internal medicine. ${ }^{7}$

In present study $53 \%$ of cases had soft plaque (type I and II plaque). Calcified plaque (Type IV) was very less ( $8 \%$ only) in the present study. In a cross-sectional study Geroulakos et al, ${ }^{8}$ found echolucent plaques to be associated with a higher incidence of brain infarcts on CT scans $(P<0.02)$. Langsfield et al had mentioned that there is increased risk of becoming symptomatic with soft plaque compared with dense, echorich plaques. ${ }^{9}$ Similar findings have been reported by $\mathrm{O}^{\prime}$ Holleran et al and Bock et al in their research. ${ }^{10,11}$

Fifty eight percent cases had less than 50\% CSA lumen narrowing due to plaque. Twenty one percent cases had $50-69 \%$ narrowing and another $21 \%$ cases had $70-99 \%$ luminal narrowing.
IMT increases linearly with age from mean of $0.48 \mathrm{~mm}$ at age 40 years to $1.02 \mathrm{~mm}$ at age 100 years. There is a formula applicable to it's $\{(0.009 x a g e)+0.116\}$ $\mathrm{mm}$. However, $0.9 \mathrm{~mm}$ is the cut off point, more than it is considered as the thickened IMT and associated with plaque. ${ }^{12,13}$ In our study it is found that mean of IMT was $0.89 \mathrm{~mm}$ and $0.88 \mathrm{~mm}$ in right and left side respectively. Similar findings were found in a cohort study conducted by Kitamura et al. ${ }^{14}$

Majority of cases had ipsilateral plaque and most of the plaques were soft type (type I and II) as described in the aforementioned paragraphs, it seems that there is likely increased risk of ischemic stroke due to the ipsilateral soft plaque.

However it was a single institution based descriptive study with convenience sampling. Due to selection criteria very limited numbers of cases were enrolled for study. Therefore the sample size was small to have conclusive evidence. It was limited in time frame and resources as well. It might not represent the true picture of the eastern region of Nepal. Possibility of the multiple biases in the different stages of the study cannot be denied.

\section{CONCLUSIONS}

Ultrasonographic evaluation of extra-cranial part of carotid artery is a non-invasive, easy to carry out, fast, inexpensive, widely available and without any proven hazards technique. However it is an operator dependant 
procedure. It can detect morphological changes like IMT and type plaque in extra-cranial carotid artery lesion. This study showed that carotid ultrasound can be used for screening of the asymptomatic but high-risk cases and following up of the symptomatic cases to plan for necessary management as required. Prospective, multicenter study, not limited in time frame and numbers would be valuable to further explore the different aspect of stroke and related risk factors, which could reflect a total clear picture prevailing in this part of the country.

\section{REFERENCES}

1. World Health Organization. The world health report 2002. Geneva: World Health Organization; 2002.

2. Zwiebel WJ, Pellerito JS. Introduction to Vascular Ultrsonography: The role of ultrasound in the management of cerebrovascular disease. $5^{\text {th }}$ ed. Philadelphia: Elsevier Inc; 2005. p. 107-131.

3. Rumack CM, Wilson SR, Charboneau JW. Diagnostic Ultrasound: The extracranial cerebral vessels. $2^{\text {nd }}$ ed. St. Louis: Mosby; 1998. Vol I p. 885-919.

4. Braunwald E, Fauci AS, Kasper DL, Longo DL, Jameson JL et al. Harrison's Principle of Internal medicine: Cerebrovascular diseases. $15^{\text {th }}$ ed. New York: McGraw-Hill; 2001. Vol II p. 2369-2391.

5. Gray-Weale AC, Graham JC, Burnett JR, Byrne K, Lusby RJ. Carotid artery atheroma: comparison of preoperative B-mode ultrasound appearance with carotid endarterectomy specimen pathology. J Cardiovasc Surg (Torino). 1988 Nov-Dec;29(6):676-81.

6. Grant EG, Benson CB, Moneta GL, Alexandrov AV, Baker JD, Bluth EI et al. Carotid artery stenosis: gray-scale and Doppler US diagnosis--Society of Radiologists in Ultrasound Consensus Conference. Radiology. 2003 Nov;229(2):340-6

7. Smith WS, Hauser SL, Easton JD. Cerebrovascular diseases. In: Braunwald E, Fauci AS, Kaspor DL, Longo DL, Jameson JL editors. Harrison's Principle of Internal medicine. $15^{\text {th }}$ ed. New York: McGraw-Hill; 2001. Vol II p. 2369-2391.
8. Geroulakos G, Domjan J, Nicolaides A, Stevens J, Labropoulos $\mathrm{N}$, Ramaswami $\mathrm{G}$ et al. Ultrasonic carotid artery plaque structure and the risk of cerebral infarction on computed tomography. J Vasc Surg. 1994 Aug;20(2):263-6.

9. Langsfeld M, Gray-Weale AC, Lusby RJ. The role of plaque morphology and diameter reduction in the development of new symptoms in asymptomatic carotid arteries. J Vasc Surg. 1989 Apr;9(4):548-57.

10. O'Holleran LW, Kennelly MM, McClurken M, Johnson JM. Natural history of asymptomatic carotid plaque. Five year follow-up study. Am J Surg. 1987 Dec;154(6):659-62.

11. Bock RW, Gray-Weale AC, Mock PA, App Stats M, Robinson DA, Irwig $L$ et al. The natural history of asymptomatic carotid artery disease. J Vasc Surg. 1993 Jan;17(1):160-9.

12. Homma S, Hirose N, Ishida H, Ishii T, Araki G. Carotid plaque and intima-media thickness assessed by b-mode ultrasonography in subjects ranging from young adults to centenarians. Stroke. 2001 Apr;32(4):830-5.

13. Zwiebel WJ, Pellerito JS. Introduction to Vascular Ultrasonography: Ultrasound Assessment of Carotid Plaque. $5^{\text {th }}$ ed. Philadelphia: Elsevier Inc; 2005. p. 155-169.

14. Kitamura A, Iso H, Imano $H$, Ohira $\mathrm{T}$, Okada $\mathrm{T}$, Sato $\mathrm{S}$ et al. Carotid intima-media thickness and plaque characteristics as a risk factor for stroke in Japanese elderly men. Stroke. 2004 Dec;35(12):2788-94 